\title{
Brain natriuretic peptide is not predictive of dilated cardiomyopathy in Becker and Duchenne muscular dystrophy patients and carriers
}

Steven Schade van Westrum ${ }^{1,6}$, Lukas Dekker ${ }^{2,7}$, Rob de Haan $^{3}$, Erik Endert ${ }^{4}$, leke Ginjaar ${ }^{5}$, Marianne de Visser ${ }^{1}$ and Anneke van der Kooi ${ }^{*}$

\begin{abstract}
Background: Cardiomyopathy is reported in Duchenne and Becker muscle dystrophy patients and female carriers. Brain Natriuretic peptide (BNP) is a hormone produced mainly by ventricular cardiomyocytes and its production is up regulated in reaction to increased wall stretching. N-terminal-proBNP (NT-proBNP) has been shown to be a robust laboratory parameter to diagnose and monitor cardiac failure, and it may be helpful to screen for asymptomatic left ventricular dysfunction. Therefore we tested whether NT-proBNP can distinguish patients with Duchenne or Becker muscular dystrophy patients and carriers of a dystrophin mutation with a dilated cardiomyopathy from those without.
\end{abstract}

Methods: In a cohort of Duchenne and Becker muscle dystrophy patients $(n=143)$ and carriers $(n=219)$ NT-proBNP was measured, and echocardiography was performed to diagnose dilated cardiomyopathy (DCM).

Results: In total sixty-one patients (17\%) fulfilled the criteria for DCM, whereas 283 patients (78\%) had an elevated NT-pro BNP. The sensitivity of NT-proBNP for DCM in patients or carriers was $85 \%$, the specificity $23 \%$, area under the ROC-curve $=0.56$. In the specified subgroups there was also no association.

Conclusion: Measurement of NT-pro BNP in patients suffering from Duchenne or Becker muscular dystrophy and carriers does not distinguish between those with and without dilated cardiomyopathy.

Keywords: Duchenne muscular dystrophy, Becker muscular dystrophy, Brain Natriuretic peptide, Dystrophinopathy carriers, Dilated cardiomyopathy

\section{Background}

It is well known that the heart is involved in Duchenne muscular dystrophy (DMD) and Becker muscular dystrophy (BMD), both caused by mutations in the dystrophin gene on the short arm of the X-chromosome (Xp21). In BMD the dystrophin function is altered in a variable way mostly due to an "in-frame" mutation but nearly always present. In DMD dystrophin is absent $(<5 \%)$ due to mainly an "out-of-frame"-mutation. Patients with DMD are found to have dilated cardiomyopathy at a median age of onset of 16.8 (range 15-18.7), whereas in BMD median onset is 30.4 (range 23.8-37.0)

\footnotetext{
*Correspondence: a.j.kooi@amc.uva.nl

'Department of Neurology, Academic Medical Centre, University of Amsterdam, Meibergdreef 9, Amsterdam 1100 DD, The Netherlands Full list of author information is available at the end of the article
}

[1]. Nearly $72 \%$ of DMD patients above the age of 18 years have echocardiographic evidence of a dilated left ventricle and a reduced ejection fraction $(<45 \%)$ [2]. We and others found a frequency of DCM in BMD patients ranging from $33-49 \%$, which was associated with the duration of the disease [3,4]. In BMD, cardiac involvement can occur in the absence of significant muscle weakness [5]. Carriers of a dystrophin-gene mutation are also at risk of cardiac involvement, often in the absence of muscle weakness [6,7]. In various study populations the incidence of dilated cardiomyopathy (DCM) among DMD carriers varied between $7 \%$ to $9 \%$, and among BMD carriers from $0 \%$ to $13 \%$ [6-8]. Brain Natriuretic peptide (BNP) is a hormone produced mainly by myocytes of the cardiac ventricular wall. Its production is upregulated in reaction to stretching of the wall as occurs in DCM. It is formed by the splicing of proBNP into 
$\mathrm{BNP}$ and the inactive $\mathrm{N}$-terminal proBNP (NT-proBNP) in a 1:1 ratio. Since NT-proBNP is more stable than BNP it is widely used as a marker. In a recent paper about the use of natriuretic peptide (NP) levels, among them BNP and NT-proBNP, in clinical practice Maisel et al. report that the role of NP levels in clinical practice is evolving rapidly and has been incorporated into most national and international cardiovascular guidelines for heart failure [9]. NP levels are found to be quantitative plasma biomarkers of heart failure (HF), are accurate in the diagnosis of HF, can accelerate accurate diagnosis of heart failure presenting in primary care, and may be helpful to screen for asymptomatic left ventricular dysfunction in high-risk patients. In DMD patients raised concentrations of BNP associated with heart failure have also been found $[10,11]$. Because DCM is considered a severe complication of DMD or BMD and may arise unnoticed in asymptomatic carriers we investigated the prevalence of DCM and the levels of NT-proBNP. A cross-sectional study among patients and carriers was performed in order to address the question whether NT-proBNP might be a marker of the presence of DCM in dystrophinopathies.

\section{Methods}

\section{Patients}

Between January 2002 and February 2005 a convenience sample of patients with DMD, BMD and carriers of these disorders were asked to participate. Since the Clinical Genetic Centre of the University Medical Centre Leiden, the Netherlands, is the referral centre for DNA testing for mutations in the dystrophin gene their database was scrutinized for eligible patients. Subsequently, the treating physicians were asked to contact these patients. Patients were also informed through the patients' support association ('Vereniging Spierziekten Nederland'). Inclusion criteria were the following: age 8 to 70 years, and a definite diagnosis of dystrophinopathy. The diagnosis was considered definite when muscle biopsy demonstrated absence of dystrophin on immunohistochemical staining (DMD), or on Western Blot, or when DNA analysis demonstrated the presence of a mutation in the dystrophin gene (DMD, BMD and carriers). Carriers could also be considered definite when pedigree analysis indicated they were obligate carriers or linkage analysis revealed a chance of more than $99 \%$ indicating that they were obligate carriers. All were assigned a functional grade based on a scale described by Brooke et al. in order to assess disability due to skeletal muscle involvement [12]. Patients or carriers were considered functionally symptomatic when they experienced disability due to muscle weakness in the upper or lower extremities or both, leading to a Brooke score $>1$ (not being able to climb stairs without aid of the railing or worse, and/or abduct the arms in a full circle until they touch above the head or worse). Patients or carriers with DCM without disability due to skeletal muscle weakness were not considered functionally symptomatic. Patients or carriers who recently had had a cardiovascular event, such as myocardial infarction or unstable angina, or who had undergone a major surgical intervention were excluded.

\section{Investigations}

The patients were invited to the out-patient department of the Academic Medical Centre, Amsterdam, the Netherlands. A standardised questionnaire was applied for symptoms suggestive of heart failure such as dyspnoea on exertion, orthopnoea, nocturia, chest pain, palpitations, dizziness or collapse and decrease of appetite. The use of medication was registered. The functional scale designed by Brooke was assessed for both upper and lower extremities [12]. The slow vital capacity, measured with a hand held spirometer, was registered as a percentage of the normal value related to age, height and gender. Blood pressure, height and weight were measured. The Body Surface Area (BSA) and Body Mass Index (BMI) were calculated. Obesity was defined as a $\mathrm{BMI}>30$.

All patients and carriers were subjected to echocardiography using a Vivid 5 GE echocardiograph equipped with a $5 \mathrm{MHz}$ transducer (LD). Parameters measured were: Left Ventricle End Diastolic Diameter (LVEDD), Left Ventricle End Systolic Diameter (LVESD), both in parasternal long axis projection. Global Left Ventricular Function (LVF) was judged as good, fair, or poor by an experienced cardiologist (L.D.) [13,14]. The Fractional Shortening Index was calculated (FSI) as follows: ((LVEDD-LVESD)/LVEDD)*100\%. The LVEDD was corrected for age and body surface area [15]. DCM was defined as an enlarged left ventricle with a global left ventricle dysfunction or fractional shortening of $28 \%$ or less, according to guidelines of the World Health Organization/International Society and Federation of Cardiology Task Force [16]. Patients were considered to suffer from chronic heart failure (CHF) when they had symptoms of heart failure, an abnormal ECG and a FSI less than $45 \%$, according tot the guidelines of the task force for the diagnosis and treatment of chronic heart failure of the European Society of Cardiology [17].

Peripheral blood was drawn by venapuncture after at least one-hour rest during the interview for $\mathrm{N}$-terminal pro-brain Natriuretic peptide (NT-proBNP) analysis using Enzyme Immunoassay, Biomedica Medizinprodukte $\mathrm{GmbH} \& \mathrm{CO} \mathrm{KG}$, Vienna, Austria. According to the manufacturer, NT-proBNP levels of less than $350 \mathrm{pmol} / \mathrm{L}$ were considered as normal. Independent investigators blinded for the results of the other parameters performed electrocardiography, echocardiography, and laboratory investigations. 


\section{Statistical analysis}

Demographic and clinical characteristics of the study group were summarized using descriptive statistics. Differences in proportions, medians and means were analysed using the $\chi^{2}$ test, Mann Whitney test, Fisher's exact test, a two-group t-test or a Mann-Whitney U test, when appropriate. The diagnostic ability of NT-proBNP was expressed in terms of sensitivity, specificity, and area under the ROC curve (AUC). In both the total study group and separate subgroups we analysed the impact of continuous and dichotomous NT-proBNP levels on DCM using multivariate logistic regression, adjusted for disease duration, weakness or complaints suggestive of heart failure. Effect size was expressed in odds ratios (OR).

With a $X^{2}$-test we additionally analysed the association between an elevated NT-proBNP and the separate parameters of DCM, viz. an enlarged LVEDD, a decreased FSI or global left ventricle hypokinesia at 2D echocardiography. We also compared the level of NT-proBNP in those receiving medication versus those who did not with a $x^{2}$ test. In addition we analysed the association between diastolic dysfunction and NT-proBNP, DCM and symptoms of heart failure with a $\chi^{2}$-test. All analyses were done with SPSS 16.0 for Windows (SPSS Inc. Illinois, USA). When subgroups were compared, they were formed on the basis of their diagnosis (see above). Carriers were further classified by whether they were functionally symptomatic, as described above, or asymptomatic. Statistical uncertainty was expressed in 95\% confidence intervals (C.I).

\section{Informed consent and funding}

The study conforms with the principles outlined in the Declaration of Helsinki and had the approval of the
Medical Ethical Committee of the Academic Medical Centre, Amsterdam, The Netherlands. All included patients gave informed consent for participation in the study. When an included patient was under the age of 18 , informed consent was also given by a parent or guardian.

The work was supported by the Prinses Beatrix Fonds, The Hague, The Netherlands.

The authors are solely responsible for the design and conduct of this study, all study analyses and drafting and editing of the paper.

\section{Results}

The data of 362 out of 404 eligible patients and carriers were available for complete analysis. Thirty-nine patients/ carriers were excluded because of missing NT-proBNP data $(n=30)$, missing echocardiography variables $(n=9)$ or the body surface area could not be calculated due to deformities $(n=3)$. A DNA mutation in the dystrophingene was present in $71 \%$ of the included patients or carriers (85\% DMD, $72 \% \mathrm{BMD}$ and $77 \%$ carriers). In the remainder diagnosis was established by immunohistochemical or -biochemical investigation of a muscle biopsy in DMD or BMD patients (13\%) or by pedigree or linkage analysis in carriers (16\%).

Demographic features and clinical characteristics of the various subgroups are shown in Table 1. Complaints suggestive of cardiac failure such as dyspnea on exertion, orthopnoea, nocturia, chest pain, palpitations were present in $11 \%$ of DMD patients, $17 \%$ of BMD patients, and $27 \%$ of the carriers, respectively. The main symptom, viz. exertional dyspnoea: was found in $2 \%$ in DMD $14 \%$ in $\mathrm{BMD}$ and $13 \%$ in carriers. Of the carrier group

Table 1 Demographic features and clinical characteristics of 362 DMD/BMD patients and carriers

\begin{tabular}{|c|c|c|c|c|c|c|}
\hline & DMD & BMD & $\begin{array}{c}\text { Functionally } \\
\text { symptomatic } \\
\text { carrier DMD }\end{array}$ & $\begin{array}{l}\text { Functionally } \\
\text { asymptomatic } \\
\text { carrier DMD }\end{array}$ & $\begin{array}{c}\text { Functionally } \\
\text { symptomatic } \\
\text { carrier BMD }\end{array}$ & $\begin{array}{c}\text { Functionally } \\
\text { asymptomatic } \\
\text { carrier BMD }\end{array}$ \\
\hline$n$ & 55 & 88 & 10 & 130 & 4 & 75 \\
\hline Median age (yr) (range) & $12(8-44)$ & $30(8-59)$ & $56(27-69)$ & $44(8-68)$ & $47(22-64)$ & $44(16-72)$ \\
\hline Median disease duration (yr) (range) & $10(4-41)$ & $20(1-52)$ & $10(0-36)$ & na & $26(7-44)$ & na \\
\hline Median vital capacity (\%) (range) & $52(14-84)$ & $88(18-161)$ & $87(69-125)$ & $106(61-203)$ & $115(41-122)$ & $108(61-166)$ \\
\hline Median diastolic blood pressure $(\mathrm{mmHg})$ (range) & $66(44-87)$ & $76(48-112)$ & $82(67-99)$ & $83(56-116)$ & $77(73-90)$ & $77(60-108)$ \\
\hline Hypertension $^{+}$ & $2(4 \%)$ & $26(30 \%)$ & $7(70 \%)$ & $54(42 \%)$ & $1(25 \%)$ & $23(31 \%)$ \\
\hline Wheelchair bound & $34(62 \%)$ & $12(14 \%)$ & $0 \%$ & na & $0 \%$ & na \\
\hline Treatment $^{\#}$ & $3(6 \%)$ & 17 (19\%) & $3(30 \%)$ & $14(11 \%)$ & $1(25 \%)$ & $4(5 \%)$ \\
\hline Any Symptom CHF* & $6(11 \%)$ & 15 (17\%) & 7 (70\%) & $30(23 \%)$ & $3(75 \%)$ & $19(25 \%)$ \\
\hline Obesity $^{\S}$ & 0 & $5(6 \%)$ & $6(30 \%)$ & $19(16 \%)$ & $1(25 \%)$ & $9(13 \%)$ \\
\hline
\end{tabular}

"Treatment: percentage of persons receiving medication including beta-blockers, diuretics, Angiotensin Converting Enzyme-inhibitors (ACE-inhibitors) or Angiotensin II type-1 inhibitors (AT-1-inhibitors).

*Symptoms of CHF: percentage with any symptom of cardiac heart failure (CHF) like nocturia, orthopnea, exercise induced dyspnoea, chest pain or dizziness.

${ }^{+}$Hypertension: blood pressure higher than $90 \mathrm{mmHg}$ diastolic or $140 \mathrm{mmHg}$ systolic.

${ }^{5}$ Obesity: Body Mass Index $>30$.

na not applicable. 
Table 2 Echocardiographic variables

\begin{tabular}{|c|c|c|c|c|c|c|}
\hline & DMD & BMD & $\begin{array}{l}\text { Functionally } \\
\text { symptomatic } \\
\text { carrier DMD }\end{array}$ & $\begin{array}{l}\text { Functionally } \\
\text { asymptomatic } \\
\text { carrier DMD }\end{array}$ & $\begin{array}{l}\text { Functionally } \\
\text { symptomatic } \\
\text { carrier BMD }\end{array}$ & $\begin{array}{l}\text { Functionally } \\
\text { asymptomatic } \\
\text { carrier BMD }\end{array}$ \\
\hline LVEDD (mm, range) & $42(35-66)$ & $54(33-77)$ & $52(43-64)$ & $50(40-69)$ & $51.5(42-58)$ & 49 (39-78) \\
\hline FSI (\%, range) & $33(5-48)$ & $30(3-48)$ & $35(14-48)$ & $33(13-55)$ & $32(24-40)$ & $34(5-52)$ \\
\hline LVF Dysfunction ${ }^{\S}$ & $20 \%$ & $34 \%$ & $14 \%$ & $10 \%$ & $0 \%$ & $3 \%$ \\
\hline
\end{tabular}

LVEDD Left Ventricle End Diastolic Diameter, FSI Factional shortening Index, LVF Left Ventricular Function.

$\S$ LVF dysfunction is any function less than good.

93\% DMD and 95\% BMD carriers were functionally asymptomatic due to the lack of skeletal muscle weakness. ACE inhibitors, $\beta$-blockers or diuretics were used by $42(12 \%)$ of patients or carriers. Eight (14\%) DMD patients received corticosteroids. None of the patients or carriers had complaints or a history of coronary artery disease. Obesity was present in 3\% (5/143) of the DMD or BMD patients and in $16 \%(35 / 219)$ of the carriers (overall 40/362, 11\%). Four DMD patients, three BMD patients and none of the carriers $(7 / 362,2 \%)$ had ventilatory support.

In total thirty-three (9\%) patients/carriers met the criteria for chronic heart failure. The echocardiographic variables are shown in Table 2. In total 283 patients/carriers $(78 \%)$ had an elevated NT-pro BNP. The pointprevalences of patients or carriers fulfilling the defined criteria for chronic heart failure (CHF) or DCM in the DMD patients were $6 \%$ and $16 \%(3 / 55$ and $9 / 55)$, respectively, in the BMD patients $14 \%$ and $32 \%(12 / 88$ and $28 / 88$ ), respectively and in the carriers $8 \%$ and $11 \%$ (18/ 219 and 24/219), respectively. Overall, DCM was present in 61 out of 362, 17\%. No significant difference in the frequencies of the presence of DCM between the groups with and without an elevated NT-proBNP was found (52/283 vs. $9 / 79$ i.e.: $18 \%$ vs. $11 \%, p$ 0.14) (Table 3$)$. There was also no significant difference in the frequencies of chronic heart failure between the groups with and without an elevated NT-proBNP (11\% vs 9\%, $p 0.06$ Chi-square). The distribution of the NT-proBNP concentration among the different disease categories is shown in Figure 1. Only in DMD patients the median NT-proBNP level is significantly higher among patients with DCM (440 vs. 840 $\mathrm{pmol} / \mathrm{L}, p$ 0.01) (Table 4).

The sensitivity (52/61) rate and specificity (70/301) rate of NT-proBNP for the presence of DCM in the whole cohort were $85 \%$ and $23 \%$, respectively. The area under the ROC curve (AUC) was 0.56 (95\% C.I.: 0.48$0.65)$ (Figure 2). The sensitivity (30/33) and specificity (76/329) rates of NT-proBNP for the presence of chronic heart failure were $91 \%$ and $23 \%$, respectively. The AUC was 0.58 (95\% C.I.: 0.49 - 0.68).

No significant association between elevated NTproBNP and DCM was found in the subgroups, i.e., DMD, BMD, asymptomatic or symptomatic carriers (data not shown) When NT-proBNP level was entered as a dichotomous independent variable (elevated or not) into a logistic regression model (adjusted for disease duration, weakness, treatment or complaints suggestive of heart failure) no statistical significant associations could be demonstrated. In DMD patients: $\mathrm{OR}=2.16$ (95\% C.I. 0.21-22.79, $p$ 0.52); in BMD patients: $\mathrm{OR}=0.92$ (95\% C.I. $0.30-2.83, p$ 0.89); in carriers: $\mathrm{OR}=4.84(95 \%$ C.I. $0.51-31.58, p 0.19)$. In the total study group the OR was 1.49 (95\% C.I. 0.67-3.34, $p$ 0.33). When NT-proBNP concentration was entered as a continuous variable into the model, the parameter did not explain the presence of $\mathrm{DCM}$ in the total study group $(\mathrm{OR}=1.87,95 \%$ C.I. 0.68 5.13, $p$ 0.23). Also, NT-proBNP was not associated with the presence of DCM in BMD patients separately $(\mathrm{OR}=1.9$ ( $95 \%$ C.I. $0.40-9.11, p 0.42)$ or carriers $(\mathrm{OR}=2.26,95 \%$ C.I. $0.40-9.75, p$ 0.40). In DMD patients the regression model could not be fitted statistically because of the low incidence of DCM in this subgroup.

Neither could we demonstrate a significant difference in the frequencies of an elevated NT-pro BNP between patients or carriers with and without an LVEDD exceeding the maximal LVEDD corrected for age and body surface area $(82 \%$ vs. $76 \%)(p$ 0.22), with or without a fractional shortening index less than $28 \%$ ( $82 \%$ vs. $77 \%$, $p$ 0.25) or with or without global left ventricle hypokinesia at 2D echocardiography ( $85 \%$ vs. $77 \%, p 0.22)$.

The frequency of an elevated (> $350 \mathrm{pmol} / \mathrm{L}$ ) NTproBNP among patients or carriers receiving medication was 39 (93\%) compared to 244 (76\%) among those without medication ( $\mathrm{p}=0.01)$. The level of NTproBNP was significantly higher in those receiving medication compared to those without (800 vs $590 \mathrm{pmol} / \mathrm{L}$, $\mathrm{p}<0.001)$.

Table 3 Elevated NT-proBNP in relation to the presence of dilated cardiomyopathy

\begin{tabular}{lcccc}
\hline & & \multicolumn{3}{c}{ DCM } \\
\cline { 3 - 4 } & & Present & Absent & \\
\hline NT-proBNP & Elevated & 52 & 231 & 283 \\
& Normal & 9 & 70 & 79 \\
& 61 & 301 & 362 \\
\hline
\end{tabular}




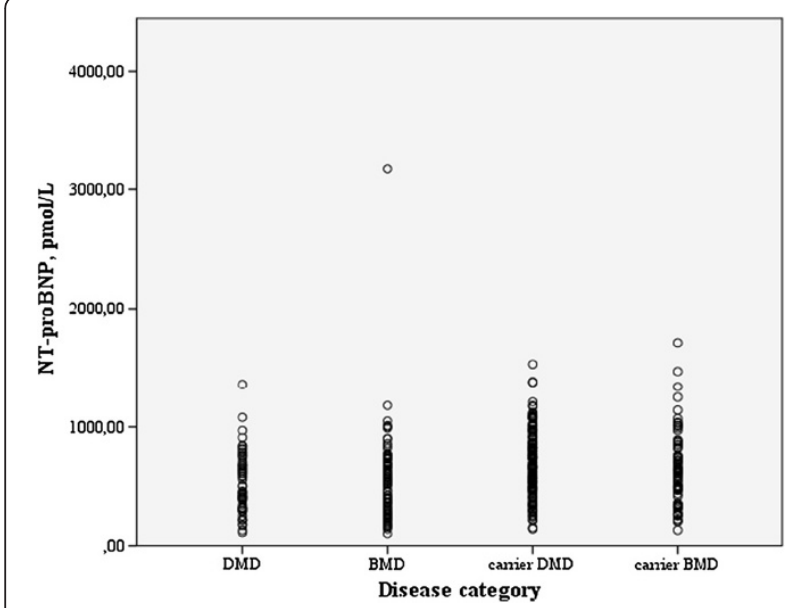

Figure 1 Distribution of concentration NT-proBNP shows no difference amongst the separate disease categories.

\section{Discussion and conclusions}

In this cross-sectional study encompassing a large number of DMD and BMD patients and carriers the overall point prevalence of dilated cardiomyopathy was $17 \%$. Across the whole group, there was no significant difference in the frequency of elevated NT-proBNP levels between individuals with or without dilated cardiomyopathy. There was no relation between an elevated NT-proBNP and DCM when corrected for disease duration, treatment any weakness or complaints of heart failure. Only in DMD patients with DCM the median NT-proBNP level was higher than in DMD patients without DCM. However, it was impossible to statistically correct for disease duration, treatment, any weakness or complaints of heart failure with a logistic regression analysis since the model did not fit. The ROC- analysis did not show a more discriminatory threshold. Our goal was to assess whether NT-proBNP might be a marker of the presence of DCM in dystrophinopathies and the study showed that the overall accuracy of the NT-proBNP test to diagnose dilated cardiomyopathy was poor.

It is of note, that complaints suggestive of cardiac failure, in particular exercise-induced dyspnoea, were most

Table 4 Median concentration NT-proBNP in pmol/L per disease category

\begin{tabular}{cccc}
\hline & \multicolumn{2}{c}{ Dilated cardiomyopathy } & \\
\cline { 2 - 3 } & Absent & Present & $\mathbf{p}^{\S}$ \\
\hline DMD (range) & $440(110-840)$ & $840(170-1360)$ & 0.01 \\
BMD median (range) & $510(100-1180)$ & $580(160-3170)$ & ns \\
Carrier DMD (range) & $660(140-1530)$ & $665(400-1380)$ & ns \\
Carrier BMD (range) & $600(130-1710)$ & $845(350-1340)$ & ns \\
Carrier overall (range) & $640(130-1710)$ & $665(350-1380)$ & ns \\
\hline
\end{tabular}

§Mann-Whitney test.

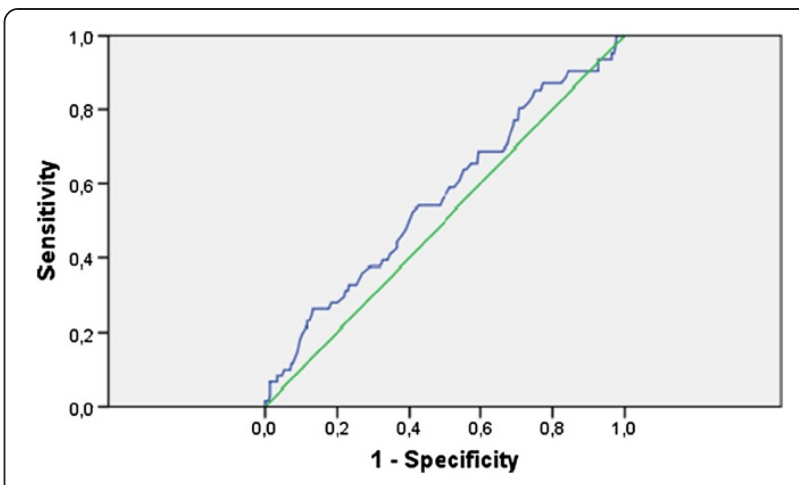

Figure 2 Receiver Operating Curve of NT-proBNP for DCM in the whole cohort.

often found in the carriers of dystrophin mutations (all carriers: 59/219, 27\%) as compared to patients with DMD (11\%) or BMD (17\%). There may be several explanations for this counterintuitive observation. First, there is no consensus about the validity and reliability of symptoms indicating chronic heart failure [17]. Second, the differences in the frequency might be explained by the interaction between physical capabilities and the severity of the loss of function of dystrophin and the inverse relationship between these two elements. None of the carriers were wheelchair bound so the cohort of carriers seems to be more capable of performing exerciserelated activities than BMD and DMD patients of whom $14 \%$ and $62 \%$ respectively were wheelchair bound. In line with that BMD patients who have intermediate function of dystrophin as compared to DMD and carriers have more complaints of heart failure than do DMD patients. Third, muscle weakness might lead to higher demands on the cardiac system in patients who remain ambulatory and consequently leads earlier to complaints of heart failure. Fourth, the higher frequency of obesity in the cohort of carriers (16\% in carriers vs. $3 \%$ in patients) is a confounding factor. However, the low percentage of obesity found in patients could be an underestimation because patients have a variable level of muscle atrophy which diminishes the total body mass.

The frequency of DCM was $11 \%$ in carriers, as compared to $16 \%$ in DMD and 32\% in BMD. Others have found prevalences up to nearly $72 \%$ of DMD patients above the age of 18 years [2]. The relatively low prevalence of DCM in our DMD patients may be explained by the fact that $80 \%$ of the patients was below the age of 20 , and by our strict definition of DCM where others used less stringent criteria, i.e., echocardiographic evidence of a dilated left ventricle and a reduced ejection fraction $(<45 \%)$ [2].

BNP has been previously studied as marker for left ventricle dysfunction in patients with Duchenne and Becker muscular dystrophy and in carriers [10,18-20]. 
Mori et al. showed a curvilinear relationship between $\mathrm{BNP}$ and the shortening fraction of the left ventricle in 63 DMD patients [10]. When the shortening fraction was found to be below 15\% the BNP level rose exponentially. Thereupon the authors concluded that BNP was a marker for a severely affected ejection fraction, but not a sensitive marker for early left ventricle dysfunction. This was confirmed by Demachi et al. and Mohyuddin et al. $[19,21]$. Demachi compared 31 patients with DMD/ BMD with 20 patients with idiopathic dilated cardiomyopathy. The former had lower levels of BNP than the latter, especially when the left ventricle ejection fraction was markedly diminished. They hypothesised that the difference may well be explained by the lesser mechanical strain of the left ventricular myocytes and epicardial fibrosis in DMD/BMD and the reduced physical activity since all patients in the study were wheelchair dependent. A linear correlation between BNP and fractional shortening or left ventricle diameter was found in 15 DMD carriers described by Adachi [20]. In 65\% of the carriers with an enlarged left ventricle and in $50 \%$ of the carriers with decreased fractional shortening an elevated $\mathrm{BNP}$ was present.

In contrast to the afore-mentioned publications we adhered to a strict definition of DCM according to the guidelines of the World Health Organisation/International Society and Federation of Cardiology Task Force, namely an enlarged LVEDD corrected for weight and age together with a global left ventricle dysfunction or a fractional shortening index (FSI) of less than $28 \%$, according to guidelines of the World Health Organisation/International Society and Federation of Cardiology Task Force [16]. The relative low incidence of DCM might explain why NT-proBNP failed to discriminate between DCM negative and DCM positive patients/carriers when corrected for age, weakness, treatment and complaints in a logistic regression analysis.

Treatment of left ventricle dysfunction in muscular dystrophies is studied in DMD patients, not in carriers. In DMD patients dysfunction of the left ventricle function can be influenced by treatment [22-25]. In trials on patients with acute or chronic heart failure on the basis of other diseases than a dystrophinopathy, it has been shown that NT-proBNP decreases if treatment of heart failure due to left ventricle dysfunction is successful $[26,27]$. Therefore it might be expected that treatment with ACE-inhibitors with or without beta-blockers irrespective of the indication of treatment in DMD or BMD can also result in a decreased level of natriuretic peptides. In the Netherlands dystrophinopathy patients and carriers tend to be treated since the frequency of treated patients or carriers was significantly higher in those with DCM compared to those without DCM. However, it seems unlikely that treatment has interfered with the diagnostic ability of NT-proBNP for DCM since patients or carriers on this medication had more often an elevated NT-proBNP and a higher mean NT-proBNP than those without DCM.

NT-proBNP was found to be significantly correlated with depressed LV function on echocardiography in a cohort of 28 wheelchair dependent DMD patients who were on a (non)invasive mechanical ventilator [11]. In contrast, our cohort was more heterogeneous showing differences in disease severity ( $2 \%$ on mechanical ventilation and 13\% wheelchair dependent), age and comorbidity. However, neither in the whole cohort nor in the separate subgroups an elevated NT-proBNP was associated with DCM. Given the relatively high sensitivity of NT-proBNP for DCM it might be considered as a screening tool but compared to the non-invasive echocardiogram, NT-proBNP does not outperform the echocardiogram as a screening tool. The heterogeneity of the cohort, the lack of association when adjusted for treatment, weakness or disease duration strengthen the conclusion that measurement of NT-pro BNP in patients suffering from Duchenne or Becker muscular dystrophy or carriers is not helpful to diagnose dilated cardiomyopathy in any phase of the disease.

\section{Competing interests}

The authors declare that they have no competing interests.

\section{Authors' contributions}

SSVW: made a substantive intellectual contribution to the submitted manuscript: design and conceptualization of the study, analysis and interpretation of the data, and drafting and revising the manuscript. LD: author, made a substantive intellectual contribution to the submitted manuscript: conceptualization of the study, interpretation of the data, and drafting and revising the manuscript. $\mathrm{RdH}$ : author, made a substantive intellectual contribution to the submitted manuscript: design of the study, analysis of the data, and drafting and revising the manuscript. EE: contributor. IG: contributor. MdV: author, made a substantive intellectual contribution to the submitted manuscript: design and conceptualization of the study, interpretation of the data, and revising the manuscript. AvdK: made a substantive intellectual contribution to the submitted manuscript: design and conceptualization of the study, interpretation of the data, and drafting and revising the manuscript. All authors read and approved the final manuscript.

\section{Acknowledgments}

We are particularly grateful to all participating patients and carriers, the Vereniging Spierziekten Nederland, the Duchenne Parent Project, the Prinses Beatrix Fonds and Dorien Standaar, research nurse. Special thanks to all neurologists, geneticists, paediatricians and rehabilitation physicians who referred patients for the study.

\section{Financial disclosures}

S.M. Schade van Westrum reports no disclosures. L. Dekker reports no disclosures.

E. Endert reports no disclosures.

I. Ginjaar reports no disclosures.

R.J. de Haan reports no disclosures.

M. de Visser reports no disclosures.

A.J. van der Kooi receives research funding from the Prinses Beatrix Fonds. 


\section{Author details}

'Department of Neurology, Academic Medical Centre, University of Amsterdam, Meibergdreef 9, Amsterdam 1100 DD, The Netherlands. ${ }^{2}$ Department of Cardiology, Academic Medical Centre, University of Amsterdam, Amsterdam, The Netherlands. ${ }^{3}$ Clinical Research Unit, Academic Medical Centre, University of Amsterdam, Amsterdam, The Netherlands. ${ }^{4}$ Laboratory of Endocrinology and Radiochemistry, Department of Clinical Chemistry Academic Medical Centre, University of Amsterdam, Amsterdam, The Netherlands. ${ }^{5}$ Department of Human Genetics, Leiden University Medical Centre, Leiden, The Netherlands. ${ }^{6}$ Current address: Department of Neurology, Martini Hospital, Groningen, The Netherlands. ${ }^{7}$ Current address: Department of Cardiology, Catharina Hospital, Eindhoven, The Netherlands.

Received: 20 January 2013 Accepted: 12 July 2013

Published: 16 July 2013

\section{References}

1. Kirchmann C, Kececioglu D, Korinthenberg R, Dittrich S: Echocardiographic and Electrocardiographic Findings of Cardiomyopathy in Duchenne and Becker?Kiener Muscular Dystrophies. Pediatr Cardiol 2005, 26:66-72.

2. Nigro G, Comi LI, Politano L, Bain RJ: The incidence and evolution of cardiomyopathy in Duchenne muscular dystrophy. Int J Cardiol 1990, 26:271-277

3. Nigro G, Comi LI, Politano L, Limongelli FM, Nigro V, De Rimini ML, Giugliano MA, Petretta VR, Passamano L, Restucci B: Evaluation of the cardiomyopathy in Becker muscular dystrophy. Muscle Nerve 1995, 18:283-291.

4. Hoogerwaard EM, de Voogt WG, Wilde AA, van der Wouw PA, Bakker E, van Ommen GJ, de Visser M: Evolution of cardiac abnormalities in Becker muscular dystrophy over a 13-year period. J Neurol 1997, 244:657-663.

5. Melacini P, Fanin M, Danieli G, Villanova C: Myocardial involvement is very frequent among patients affected with subclinical Becker's muscular dystrophy. Circulation 1996, 94:3168-3175.

6. Hoogerwaard EM, van der Wouw PA, Wilde AA, Bakker E, Ippel PF, Oosterwijk JC, Majoor-Krakauer DF, van Essen AJ, Leschot NJ, de Visser M: Cardiac involvement in carriers of Duchenne and Becker muscular dystrophy. Neuromuscul Disord 1999, 9:347-351.

7. Grain L, Cortina-Borja M, Forfar C, Hilton-Jones D, Hopkin J, Burch M: Cardiac abnormalities and skeletal muscle weakness in carriers of Duchenne and Becker muscular dystrophies and controls. Neuromuscul Disord 2001, 11:186-191.

8. Politano L, Nigro V, Nigro G: Development of cardiomyopathy in female carriers of Duchenne and Becker muscular dystrophies. JAMA 1996, 275:1335-1338.

9. Maisel A, Mueller C, Adams K, Anker SD, Aspromonte N, Cleland JGF, Cohen-Solal A, Dahlstrom U, DeMaria A, Di Somma S, Filippatos GS, Fonarow GC, Jourdain P, Komajda M, Liu PP, McDonagh T, McDonald K, Mebazaa A, Nieminen MS, Peacock WF, Tubaro M, Valle R, Vanderhyden M, Yancy CW, Zannad F, Braunwald E: State of the art: using natriuretic peptide levels in clinical practice. Eur J Heart Fail 2008, 10:824-839.

10. Mori K, Manabe T, Nii M, Hayabuchi Y, Kuroda Y, Tatara K: Plasma levels of natriuretic peptide and echocardiographic parameters in patients with Duchenne's progressive muscular dystrophy. Pediatr Cardiol 2002, 23:160-166.

11. van Bockel EAP, Lind JS, Zijlstra JG, Wijkstra PJ, Meijer PM, van den Berg MP, Slart RHJA, Aarts LPHJ, Tulleken JE: Cardiac assessment of patients with late stage Duchenne muscular dystrophy. Neth Heart J 2009, 17:232-237.

12. Brooke M, Fenichel G, Griggs R, Mendell J: Duchenne muscular dystrophy. Neurology 1989, 39:475-481.

13. Deutsch HJ, Curtius JM, Leischik R, Sechtem U, Maschler C, de Vivie ER, Hilger $\mathrm{HH}$ : Reproducibility of assessment of left-ventricular function using intraoperative transesophageal echocardiography. Thorac Cardiovasc Surg 1993, 41:54-58.

14. Silcocks PB, Munro JF, Steeds RP, Channer KS: Prognostic implications of qualitative assessment of left ventricular function compared to simple routine quantitative echocardiography. Heart 1997, 78:237-242.

15. Henry WL, Gardin JM, Ware JH: Echocardiographic measurements in normal subjects from infancy to old age. Circulation 1980, 62:1054-1061.

16. Who ISFCTF: Report of the WHO/ISFC task force on the definition and classification of cardiomyopathies. Br Heart J 1980, 44:672-673.
17. Authors/Task Force Members: The Task Force for the Diagnosis and Treatment of Chronic Heart Failure of the European Society of Cardiology. Eur Heart J 2005, 2005(26):1115-1140.

18. Kashiwagi $\mathrm{S}$, Akaike $\mathrm{M}$, Kawai $\mathrm{H}$ : Estimation of cardiac function by plasma concentration of brain natriuretic peptide in patients with Duchenne muscular dystrophy. Rinsho Shinkeigaku 1996, 36:7-11. abstract.

19. Demachi J, Kagaya Y, Watanabe J, Sakuma M, Ikeda J, Kakuta Y, Motoyoshi I, Kohnosu T, Sakuma H, Shimazaki S, Sakai H, Kimpara T, Takahashi T, Omura K, Okada M, Saito H, Shirato K: Characteristics of the increase in plasma brain natriuretic peptide level in left ventricular systolic dysfunction, associated with muscular dystrophy in comparison with idiopathic dilated cardiomyopathy. Neuromusc Dis 2004, 14:732-739.

20. Adachi K, Kawai H, Saito M, Naruo T, Kimura C, Mine H, Inui T, Kashiwagi S, Akaike M: Plasma levels of brain natriuretic peptide as an index for evaluation of cardiac function in female gene carriers of Duchenne muscular dystrophy. Intern Med 1997, 36:497-500.

21. Mohyuddin T, Jacobs IB, Bahler RC: B-type natriuretic peptide and cardiac dysfunction in Duchenne muscular dystrophy. Int J Cardiol 2007, 119:389-391.

22. Duboc D, Meune C, Lerebours G, Devaux J-Y, Vaksmann G, Bécane H-M: Effect of perindopril on the onset and progression of left ventricular dysfunction in Duchenne muscular dystrophy. J Am Coll Cardiol 2005, 45:855-857

23. Silversides C: Effects of deflazacort on left ventricular function in patients with Duchenne muscular dystrophy. Am J Cardiol 2003, 91:769-772.

24. Kajimoto H, Ishigaki K, Okumura K, Tomimatsu H, Nakazawa M, Saito K, Osawa M, Nakanishi T: Beta-blocker therapy for cardiac dysfunction in patients with muscular dystrophy. Circ J 2006, 70:991-994.

25. Ramaciotti C, Scott WA, Lemler MS, Haverland C, lannaccone ST: Assessment of Cardiac Function in Adolescents With Duchenne Muscular Dystrophy: Importance of Neurohormones. J Child Neurol 2002, 17:191-194.

26. Gackowski A, Isnard R, Golmard J-L, Pousset F, Carayon A, Montalescot G, Hulot J-S, Thomas D, Piwowarska W, Komajda M: Comparison of echocardiography and plasma B-type natriuretic peptide for monitoring the response to treatment in acute heart failure. Eur Heart J 2004, 25:1788-1796.

27. Taniguchi R, Sato Y, Nishio Y, Kimura T, Kita T: Measurements of baseline and follow-up concentrations of cardiac troponin-T and brain natriuretic peptide in patients with heart failure from various etiologies. Hear Vessel 2006, 21:344-349.

doi:10.1186/1471-2377-13-88

Cite this article as: Schade van Westrum et al:: Brain natriuretic peptide is not predictive of dilated cardiomyopathy in Becker and Duchenne muscular dystrophy patients and carriers. BMC Neurology 2013 13:88.

\section{Submit your next manuscript to BioMed Central and take full advantage of:}

- Convenient online submission

- Thorough peer review

- No space constraints or color figure charges

- Immediate publication on acceptance

- Inclusion in PubMed, CAS, Scopus and Google Scholar

- Research which is freely available for redistribution 